\title{
O REGIME DIFERENCIADO DE CONTRATAÇÕES PÚBLICAS E UM NOVO PANORAMA LICITATÓRIO NO BRASIL
}

\author{
DIFFERENTIATED SYSTEM OF \\ PUBLIC PROCUREMENT (RDC) EW \\ BIDDING PANORAMA IN BRAZIL
}

\section{Cristina Mendes Bertoncini Corrêa ${ }^{1}$}

\section{Roberta Zumblick Martins da Silva ${ }^{2}$}

Resumo: O presente artigo científico trata do Regime Diferenciado de Contratações Públicas (RDC) no Brasil. O seu objetivo principal é estudar solução diferenciada para o regime licitatório brasileiro. Para tanto, utiliza-se a técnica de pesquisa bibliográfica, com método de abordagem dedutivo, que consiste na aplicação de regras na pesquisa jurídica para se chegar a uma conclusão, partindo-se de premissas gerais licitação pública - para verificar seus desdobramentos, ou seja, um novo regime licitatório consagrado no Regime Diferenciado de Contratações Públicas. Para atingir esse escopo, inicialmente, realiza-se análise histórica da Licitação no Brasil. Em seguida, aborda-se sobre o Regime Diferenciado (RDC). Após, traz-se à baila suas principais caracte- rísticas e inovações. Porém, conclui-se que só a mudança na legislação não é o suficiente para a mudança no comportamento da Administração Pública, o que se pressupõe, se dará, paulatinamente, com a inserção desse novo regime nas Administrações.

Palavras-chaves: Licitação. Regime diferenciado de contratações públicas. Histórico.

Abstract: This paper is about the Differentiated System of Public Procurement (RDC) in Brazil. Its main objective is to study a different solution for the Brazilian bidding regime. For this, we used the bibliographical research technique, deductive approach method, which involves the application of rules on legal research to come to

1 Graduada e Mestra em Direito pela Universidade Federal de Santa Catarina (UFSC). Atua como professora de Graduação e Pós-Graduação em Direito Administrativo. Atualmente, é professora da UFSC no Escritório Modelo de Advocacia (EMAJ), em regime de dedicação exclusiva. Autora de livros na área de direito público. Advogada. E-mail: cristina.bertoncini@gmail.com

2 Graduada em Direito pela Faculdade Cesusc, advogada. E-mail: robertazumblickms@ gmail.com 
a conclusion, starting from general premises-public bidding-to check its development, (blavla) a new bidding system in the Differentiated System of Public Procurament. To achieve this scope was initially performed a historical analysis of the bidding in Brazil. Then, a discussion of the Differentiated Regime (RDC) was performed. After it shows up its main features and innovations. However, it appears that only the change in legislation is not enough to change the behavior of the Public Administration, which is assumed, will be made gradually, with the insertion of this new regime in administrations.

Keywords: Public bidding. RDC. History of legislation.

\section{INTRODUÇÃO}

O presente artigo faz uma apresentação histórica da disciplina de licitações e contratos, indo desde a Lei Federal $n^{\circ}$ 8.666/1993 até o momento da instituição do Regime Diferenciado de Contratação.

Na pesquisa expõem-se o cenário histórico e o cenário político da concepção da Lei Federal no 8.666/1993, o primeiro diploma legal da disciplina licitatória em um estado democrático. Destacam-se, ainda, as principais alterações que ocorreram na disciplina normativa de licitações e contratos administrativos desde a promulgação da Lei Federal no 8.666/1993. Aponta-se, também, o contexto de insatisfação a respeito do modelo licitatório vigente, a qual deu ensejo à instituição do novo regime.

Passa-se, então, a se tratar do Regime Diferenciado de Contratações. Apresenta-se sua proposta inicial de ser um regime transitório e com objetos restritos, e mostra-se como ocorreu o alargamento gradual de sua aplicação, bem como a superação do seu caráter transitório.

\section{A CAMINHO DO REGIME DIFERENCIADO DE CONTRATAÇÕES}

No dia 4 de agosto de 2011 foi publicada a Lei Federal $\mathrm{n}^{\circ}$ 12.462, prevendo o Regime Diferenciado de Contratações, 
disciplina licitatória diferenciada, para atender às urgências de contratações públicas em virtude dos compromissos com grandes eventos esportivos assumidos pelo País.

Uma solução diferenciada para a disciplina de licitações e contratos administrativos, exige a compreensão de sua conjuntura e do modelo para o qual esta solução é proposta. Para tanto, far-se-á um apanhado histórico da disciplina licitatória no Brasil, a partir da promulgação da Lei Geral de Licitações Lei Federal no 8.666/1993 -, pontuando algumas de suas principais alterações, até o momento da concepção do Regime Diferenciado de Contratações e as principais alterações que este apresenta no âmbito de sua aplicação.

A Lei Federal $n^{\circ} 8.666$ foi promulgada em 21 de abril de 1993 e instituiu normas para licitações e contratos da Administração Pública, regulamentando o inciso XXI do art. 37 da Constituição Federal de $1988^{3}$.

O momento histórico da promulgação do diploma é de grande relevância para a compreensão de seu conteúdo; afinal, foi a primeira vez que a disciplina de licitações e contratos foi tratada em um ambiente efetivamente democrático ${ }^{4}$. André Janjácomo Rosilho (2011, p. 48) sustenta que o momento era impregnado pela confiança no papel transformador do direito, havendo a valorização dos princípios jurídicos, como legalidade e moralidade, o que, de certa forma, ofuscava a preocupação com a qualidade e a eficiência da gestão pública.

A proposta inicial para o texto da lei foi apresentada em

3 Art. 37 [...] XXI-ressalvados os casos especificados na legislação, as obras, serviços, compras e alienações serão contratados mediante processo de licitação pública que assegure igualdade de condições a todos os concorrentes com cláusulas que estabeleçam obrigações de pagamento, mantidas as condições efetivas da proposta, nos termos da lei, o qual somente permitirá as exigências de qualificação técnica e econômica indispensáveis à garantia do cumprimento das obrigações.

4 As alterações anteriores adotavam um instrumento jurídico típico do regime militar, o decreto-lei, que permitia ao Presidente da República aprovar normas esquivando-se do controle do Congresso Nacional. 
7 de agosto de 1991 pelo Deputado Luiz Roberto Pontes, por meio do Projeto de Lei $\mathrm{n}^{\circ}$ 1.491. Carlos Pinto Coelho Motta $(2005$, p. 20) aponta que muitos outros projetos de lei influenciaram a redação da Lei Federal no 8.666/1993, pois desde a promulgação da Constituição, esses já vinham sendo discutidos, ainda que de forma assistemática; oferecendo, portanto, ao texto final aprovado, subsídios, discordâncias e alternativas.

Destaca-se que, no momento de propositura do Projeto de Lei ${ }^{\circ}$ 1.491/1991, Fernando Collor de Mello completava pouco mais de um ano como Presidente da República e desde o início do ano de 1991 começavam a surgir suspeitas de superfaturamento de compras em sua administração. Como é de amplo conhecimento, a sequência de eventos levou ao impeachment do Presidente e sua posterior cassação. Rosilho (2011, p.76) comenta que o ambiente político do Congresso Nacional e o surgimento de uma série de escândalos envolvendo o governo conferiam a oportunidade de alterar o diploma que regulava o foco de corrupção do momento: as contratações públicas. O autor ainda assinala que:

Outra relevante consequência desta transformação [...] foi a redefinição do eixo da disciplina jurídica das licitações, que passou a se centrar no combate à corrupção. Dessa forma, ganhou força a ideia de que seria possível, através de regras jurídicas precisas e bem dirigidas, conformar a ação dos agentes públicos e privados, evitando-se com isso práticas ilícitas e imorais nas contratações estatais. Tem início a cultura administrativa dos procedimentos em oposição à de resultados. (ROSILHO, 2011, p.49).

A Lei Federal $n^{\circ} 8.666 / 1993$ toma como ponto de partida a normativa anterior: o Decreto-Lei $\mathrm{n}^{\mathrm{o}} 2.300 / 1986^{5}$. O autor Carlos Pinto Coelho Motta (2005, p. 19) reporta como sábia

5 O Decreto-Lei ${ }^{\circ}$ 2.300/1986 é o primeiro diploma legal que trata da matéria licitatória após a redemocratização do País. No entanto, este ainda guarda raízes da época ditatorial, a mencionar sua instituição por decreto-lei e não por meios democráticos. 
a atitude do legislador, qual seja, a de reparar na ausência de regulamentação para o Decreto-Lei, para assim conferir caráter minucioso a Lei Federal no 8.666/1993 - o que tornaria sua aplicação independente de regulamentação superveniente. $\mathrm{O}$ texto exaustivo levaria a unificação dos procedimentos.

André Janjácomo Rosilho (2011, p. 72) aponta que a Lei Federal n. 8.666/1993 foi concebida sobre o mesmo modelo jurídico de regulação das contratações públicas do Decreto-Lei ${ }^{\circ}$ 2.300/1986. No entanto, no caso da Lei, apostou-se com mais intensidade na noção de que normas jurídicas poderiam fornecer todos os parâmetros à boa contratação, diminuindo ainda mais a função dos agentes públicos no processo de contratações governamentais.

No mesmo sentido, Luiz Felipe Hadlich Miguel (2013, p. 409) comenta que a Lei Federal $n^{\circ} 8.666 / 1993$ é uma junção do que os diplomas anteriores ${ }^{6}$ tinham de melhor. Pontua que uma diferença marcante é que o diploma em comento foi editado em um momento político delicado, pois o País estava aprendendo a viver em um regime democrático e tendo de lidar com a corrupção, demasiadamente fora de controle. Atribui também a esse fato a tônica da legislação de cercear ao máximo a discricionariedade do Administrador Público; assevera, contudo, que, passados 20 anos, é possível afirmar que o objetivo de impossibilitar a depravação e a imoralidade, almejado pela lei, não foi alcançado.

No decorrer dos seus vinte anos de vigência, a Lei Federal $\mathrm{n}^{\mathrm{o}} 8.666 / 1993$, bem como toda a disciplina de licitações e contratos, vem incorporando atualizações e alterações das mais variadas. Durante sua existência conturbada, foram promulgadas sucessivas Medidas Provisórias, diversas Leis e uma série de regulamentos em decretos, portarias e instruções normati-

6 Código de Contabilidade Pública - Decreto n 4.536/1922, Decreto-Lei no 200/1967 e Decreto-Lei n ${ }^{\circ}$ 2.300/1986. 
vas (MOTTA; BICALHO, 2011, p. 24).

A atividade legislativa que seguiu a edição da Lei Federal $\mathrm{n}^{\mathrm{o}} 8.666 / 1993$ buscou ora alterar dispositivos do diploma, ora criar regimes específicos de licitação, ou simplesmente excluir de situações determinadas a incidência das normas da Lei Federal $n^{\circ} 8.666 / 1993$. As iniciativas, mesmo que diferentes entre si, apresentavam como denominador comum a vontade de afastar o regime jurídico da Lei Geral de Licitações e Contratos (ROSILHO, 2011, p. 125).

Rosilho (2011, p. 125) defende que, no momento da edição da lei, a tendência era a de reduzir a discricionariedade administrativa - como quem busca a "morte" do Administração -; após a promulgação da lei, porém, perceberam-se uma série de problemas. Surgiu então, a tendência de buscar eliminar a licitação.

As principais alterações da disciplina de licitações e contratos administrativos apontadas pela doutrina ocorreram tanto na própria Lei Federal $n^{\circ}$ 8.666/1993 como em diplomas apartados, quais sejam: as concessões, o pregão e o tratamento as microempresas e empresas de pequeno porte.

Dentre as alterações legislativas, percebe-se a intenção do legislador de impedir a incidência das normas da Lei Federal nº 8.666/1993 em casos específicos. É válido o destaque do seu art. 24, que prevê o rol de hipóteses de dispensa de licitação: na redação original havia a previsão de 15 hipóteses; após inúmeras reformas, o artigo passou a prever 33 hipóteses $^{7}$. André Janjácomo Rosilho (2011, p. 152) ressalta que as hipóteses de dispensa inseridas na lei, além de muitas, foram bem pontuais, referindo-se a eventos particulares. Destaca também que é possível perceber que as alterações foram editadas para favorecer

7 Logo após o surgimento da Lei $n^{0} 8.666 / 93$, a partir da edição da Lei $n^{\circ}$ 8.883/94, o rol do art. 24 sofreu diversas modificações importantes, seja para alterar a redação de seus dispositivos, seja para acrescentar novas hipóteses de dispensa de licitação. Outras hipóteses foram acrescentadas pelas Leis Federais de $\mathrm{n}^{0}:$ 9.648/98, 10.973/04, 11.107/05, 11.445/07, 11.484/07, 11.783/08, 12.188/10 e 12.349/10. (ROSILHO, 2011, p. 152). 
políticas públicas mais amplas e beneficiar entes específicos da administração pública.

A promulgação da Lei Federal no 8.987/1995, chamada de Lei das Concessões, representou a primeira insurgência ao modelo contratual da Lei Federal no 8.666/1993. As concessões são muito mais antigas que a própria Lei; entretanto, esta foi responsável por organizar o instituto e conferir-lhe maior segurança jurídica (ROSILHO, 2011, p. 181).

Entre as principais inovações da Lei Federal no 8.987/1995 estão: a permissão para que os conflitos dos contratos se resolvam por mecanismos privados; e o fato de não se exigir projeto básico para a licitação. A Lei Federal no 8.987/1995 prevê a aplicação do regime da Lei Federal no 8.666/1993 para a seleção dos proponentes, com as devidas adaptações aos preceitos especiais da Lei de Concessões (ROSILHO, 2011, p. 181).

Posteriormente, a Lei Federal $n^{0}$ 11.079/2004 criou as chamadas concessões especiais, também conhecidas como Parcerias Público-Privadas (CARVALHO FILHO, 2012, p. 364)

André Janjácomo Rosilho (2011, p. 182) afirma que a reforma legislativa operada pela Lei das Parcerias Público-Privadas também contribuiu para a flexibilização dos modelos contratuais, uma vez que possibilitou a expansão e diversificação das concessões.

No mesmo caminho de mudanças foi criada a modalidade pregão pela Lei Federal n ${ }^{\circ}$ 9.472/1997, para ser usada somente no âmbito da Agência Nacional de Telecomunicações (ANATEL). A modalidade teve aos poucos o seu alcance ampliado por diversos diplomas, mas só foi aberta para toda Administração Pública Nacional pela Lei Federal n ${ }^{\circ}$ 10.520/2002 (NIEBUHR, 2013, p. 197).

A criação da nova modalidade o correu em virtude de muitas reclamações dos órgãos administrativos a respeito da falta 
de celeridade para as contratações administrativas nas modalidades previstas na Lei Federal no 8.666/1993. As reclamações não tratavam de contratos de grande vulto ou complexidade, mas de contratos mais singelos, que eram prejudicados pelas soluções burocráticas do processo de licitação. Assim, foi criada a nova modalidade, com disciplina e procedimentos próprios, objetivando acelerar os processos de contratação nas hipóteses determinadas (CARVALHO FILHO, 2012, p. 300).

O pregão pode ser adotado para as aquisições de bens e serviços de natureza comum, o que significa, pela definição da própria legislação, bens e serviços que possam ser definidos de forma objetiva pelo edital, por especificações usuais do mercado. Assim, a adoção da modalidade não depende do valor do contrato, que era o critério utilizado para as modalidades da Lei Federal no 8.666/1993. (NIEBUHR, 2013, p. 198). Destacam-se os comentários de André Janjácomo Rosilho (2011, p. 160) a respeito dos critérios de adoção do pregão:

Nota-se, assim, que a Lei $\mathrm{n}^{\circ} 10.520 / 02$, também neste ponto em específico, evitou condicionar a administração, a priori, a rígidos critérios legais; o emprego de conceitos fluidos - bens e serviços comuns - faz, naturalmente, com que o enfrentamento do caso concreto passe a ser extremamente relevante para a aferição de validade da solução adotada pelo gestor público.

A Lei Federal $n^{\circ} 10.520 / 2002$ é sucinta e objetiva, apresentando somente treze artigos. $\mathrm{O}$ legislador reconhece que o diploma não dispõe de todas as normas necessárias à condução do procedimento licitatório; por isso, prevê no art. $9^{\circ}$ a aplicação subsidiária da Lei Federal n 8.666/1993. Mas só se irá recorrer à legislação mais antiga nos casos em que a Lei do Pregão for realmente omissa; e, sempre que houver contradição entre os diplomas, deverá prevalecer a Lei Federal $\mathrm{n}^{\circ}$ 10.520/2002 (NIEBUHR, 2013, p. 63). 
A promulgação da Lei Complementar $n^{\circ}$ 123/2006 instituiu o Estatuto da Microempresa e Empresa de Pequeno Porte, como regulamentação dos arts. $170, \mathrm{IX}^{8}$ e $179^{9}$ da Constituição Federal. O diploma traz uma série de normas específicas com o escopo de propiciar tratamento diferenciado a estas em presas como forma de reconhecimento de sua importância no setor econômico (CARVALHO FILHO, 2012, p. 313).

Do exame deste breve recorte, é possível perceber a complexidade que tomou a disciplina legal das licitações e contratos administrativos. Joel Menezes Niebuhr (2013, p. 64), critica o fato de a legislação sobre licitação pública compor um verdadeiro "cipoal", dificultando a atuação de seus intérpretes, em especial dos agentes administrativos, que precisam recorrer a uma série de diplomas legislativos, muitas vezes contraditórios entre si. A situação é agravada pelo fato de o principal diploma legislativo - a Lei Federal no 8.666/1993 - ser muito mal redigido: prescreve normas desconexas, contraditórias, não é sistêmico e o seu teor enseja uma série de dubiedades.

Assim, como mencionado, a Lei Federal $n^{\circ}$ 8.666/1993 passou por uma série de alterações, mas, ainda assim, permanecia uma insatisfação em relação aos modelos licitatórios e contratuais disponíveis, a qual se traduz em uma multiplicidade de propostas para a sua substituição. Há perante o Congresso Nacional a tramitação de muitos projetos de alteração da disciplina licitatória, prevendo inclusive a revogação ${ }^{10}$ da Lei

8 art. 170 [...] IX - tratamento favorecido para as empresas de pequeno porte constituídas sob as leis brasileiras e que tenham sua sede e administração no País.

9 art. 179 A União, os Estados, o Distrito Federal e os Municípios dispensarão às microempresas e às empresas de pequeno porte, assim definida sem lei, tratamento jurídico diferenciado, visando a incentivá-las pela simplificação de suas obrigações administrativas, tributárias, previdenciárias e creditícias, ou pela eliminação ou redução destas por meio de lei.

10 A título exemplificativo, destaca-se: em 1997 foi publicado no DOU texto designado como Anteprojeto de Nova Lei de Licitações, apelidado de Anteprojeto Bresser, no ano de 2012 foi publicado o Anteprojeto de Lei Geral de Contratações da Administração Pública, em 2003 foi encaminhado o PL no 146/2003 e em 2007 o PL no 7.907/2007. Todos esses acabaram se diluindo nos trâmites parlamentares, sem lograr aprovação final. (MOTTA; BICALHO, 2012, p. 26). 
Federal no 8.666/1993 (JUSTEN FILHO, 2013, p. 13).

Assim, a subsistência da Lei Federal no 8.666/1993 não se dá em virtude de adesão e anuência ao seu conteúdo, mas pela inexistência de consenso quanto ao modelo adequado para substituí-la. As críticas à Lei Federal n. 8.666/1993 são dotadas de grande disparidade, apresentando, muitas vezes, argumentos contraditórios entre si. Existe concordância somente acerca da necessidade de reforma da disciplina legislativa; não a respeito das soluções a serem adotadas (JUSTEN FILHO, 2013, p.14).

Motta e Bicalho (2012, p. 24) mencionam que as manifestações críticas da Lei Federal no 8.666/1993 apresentam um viés comum, que é a confusão da letra da lei com o comportamento administrativo que dela resulta, visto que este absorve as implicações da realidade das repartições públicas e as distorções da burocracia e da cultura organizacional. A crítica, assim, é deslocada e dirige-se ao modo pelo qual as licitações são conduzidas na realidade das entidades públicas, e não propriamente às prescrições legais em sua compreensão literal ou hermenêutica.

A insatisfação com a Lei Federal no 8.666/1993 é pacífica; entretanto, não há uma avaliação precisa a respeito dos "defeitos" da disciplina vigente. Há, assim, uma grande incerteza no que diz respeito às modificações mais apropriadas a serem implementadas na disciplina de licitações e contratações públicas. Teme-se que eventuais soluções menos formais e rigorosas possam resultar em graves desvios, mesmo que os formalismos do modelo atual não impeçam a ocorrência desse problema (JUSTEN FILHO, 2013, p. 14).

Neste contexto foi criado o Regime Diferenciado de Contratação, sob a justificativa de o País estar atrasado no tocante ao cumprimento dos encargos necessários para a realização da Copa do Mundo de Futebol da FIFA em 2014 e das Olimpíadas e Paraolimpíadas de 2016, e de o regime tradicional de licitação pública ser insuficiente, por demandar de tempo que 
a Administração já não possuía (NIEBUHR, 2013, p. 655).

A ausência de concordância acerca do novo modelo a ser implementado conduziu a uma solução provisória, para ser testada na vida real. Assim, a disciplina do Regime Diferenciado de Contratação propicia uma espécie de "experimentação legislativa", para a implantação gradual e controlada de um novo modelo licitatório. Como o novo modelo não revoga o anterior, há a convivência entre os dois sistemas licitatórios, sem que haja uma ruptura radical, pois a adoção do novo regime não é obrigatória, mas sim facultativa. Marçal Justen Filho (2013, p. 15) sustenta que não seria exagerada a afirmação de uma verdadeira competição entre os dois sistemas. A experiência prática irá conduzir a sobrevivência do sistema mais satisfatório, aquele que revelar maior aptidão para satisfazer as necessidades da Administração.

\section{REGIME DIFERENCIADO DE CONTRATAÇÕES PÚBLICAS E SUAS NOVIDADES}

O Regime Diferenciado de Contratações foi instituído pela Medida Provisória ${ }^{\circ} 527$, que foi convertida na Lei Federal $n^{\circ}$ $12.462 / 2011^{11}$. A lei consagra uma disciplina diferenciada para as licitações públicas e algumas regras aplicáveis aos contratos administrativos (JUSTEN FILHO, 2013, p. 17).

O Regime Diferenciado de Contratações foi concebido para ser transitório e apresentava objeto restrito a realização das obrigações assumidas pelo Brasil com relação aos eventos esportivos que sediará, como se pode conferir na redação original do seu art. $1^{\circ}$. No entanto, verificou-se a ampliação da

11 O vício formal alegado nas Ações que questionam a constitucionalidade da Lei Federal $\mathrm{n}^{\circ}$ 12.462/2011 está no fato de o Regime Diferenciado de Contratações não fazia parte da Medida Provisória ${ }^{\circ}$ 527, foi incluído somente na sua conversão em lei, sem passar pelo processo legislativo devido. 
aplicação da Lei no 12.462/2011, por diversos diplomas legislativos, perdendo assim seu caráter transitório (JUSTEN FILHO, 2013, p. 17).

Essa ampliação de abrangência do Regime Diferenciado de Contratações já era antevista pela Doutrina. Em momento anterior à Medida Provisória $n^{\circ}$ 630/2013, Joel Menezes Niebuhr (2013, p. 656) ponderava que, a despeito da avaliação subjetiva dos méritos do novo regime e dos questionamentos sobre sua constitucionalidade, não havia lógica, na visão "oficial" da Administração Pública - que festeja as suas supostas vantagens e destaca a maior celeridade dos processos licitatórios -, em se manter o regime restrito aos eventos esportivos, ao PAC, saúde e educação. O autor observa que a postura do Governo Federal aponta para uma tendência de ampliação; critica, todavia, o viés autoritário no qual o novo modelo tem sido ampliado, por Medidas Provisórias inconstitucionais, sem um debate amadurecido.

A respeito da forma de ampliação do alcance do Regime Diferenciado de Contratações, destacam-se as observações de Eduardo Carvalho Rego (2013, p. 1233):

A lamentar apenas a maneira pela qual o RDC está crescendo e tomando o espaço que anteriormente era (e que, por ausência de norma jurídica em sentido contrário, ainda deveria ser) da atual Lei de Licitações. Travestido de um regime de exceção, ele parece estar promovendo mudanças estruturais no direito público brasileiro sem o devido e necessário debate no seio da comunidade jurídica. Do modo como está sendo feito - por meio de emendas aos projetos de conversão de medidas provisórias - o RDC deixa um pouco a desejar nos quesitos transparência e legitimidade.

Marçal Justen Filho (2013, p. 16), afirma que os eventos esportivos foram utilizados para a consagração de uma reforma legislativa que tinha sua implementação obstada por controvérsias e divergências. Isso indica que, por mais que o novo 
regime licitatório tenha sido previsto para um certo contexto, o exaurimento dessas circunstâncias não irá eliminar a aplicabilidade do novo regime, que tenderá a substituir o anterior.

Conquanto as previsões de Marçal Justen Filho estejam amparadas pelas movimentações legislativas, é essencial salientar que o Regime Diferenciado de Contratações não revoga a Lei Federal $n^{\circ} 8.666 / 1993$, mas convive em paralelo a esta. E, ainda assim, mesmo nas hipóteses em que autoriza a adoção do novo regime, não lhe torna obrigatório, cabendo ao agente administrativo a escolha entre o regime da Lei Federal ${ }^{\circ}$ 8.666/1993 ou da Lei Federal n ${ }^{\mathrm{o}}$ 12.462/2011. (NIEBUHR, 2013, p. 656)

A Lei Federal no 12.462/2011 apresenta também outra particularidade: estabelece que, salvo nos casos expressamente previstos na própria lei, nas licitações que adotarem o Regime Diferenciado de Contratação haverá o afastamento das normas da Lei Federal $n^{\circ}$ 8.666/1993. Trata-se de colocação restritiva ao conteúdo da lei geral de licitações, que veda sua aplicação subsidiária nos casos em que não houver autorização explícita na própria lei. Assim, não cabe à Lei Federal no 8.666/1993 preencher eventuais lacunas do Regime Diferenciado de Contratações (MOTTA; BICALHO, 2012, p. 34).

Marçal Justen Filho (2013, p. 39) ao comentar os objetivos do RDC previstos no art. $1^{\circ}$ afirma que todos os regimes licitatórios são orientados a ampliar a eficiência, promover a competitividade, assegurar a isonomia e conduzir a seleção da proposta mais vantajosa a administração. Assim, o que diferencia o RDC não são as finalidades que o norteiam, mas o fato de ser uma solução técnico-jurídica diferenciada para promover os fins buscados em qualquer procedimento de contratação administrativa. Dessa forma, as disposições do precitado $\S 1^{\circ}$ são mais que um critério interpretativo das normas da Lei Federal $\mathrm{n}^{\mathrm{o}} 12.462 / 2011$, porquanto fornecem os objetivos a ser buscados pela autoridade administrativa. 
Ricardo Barretto de Andrade e Vitor Lanza Veloso (2012, p. 31) salientam que o princípio da eficiência atua como um norte para os objetivos e diretrizes do Regime Diferenciado de Contratações, dentre eles a necessidade de conferir maior celeridade as licitações e contratações para possibilitar o cumprimento dos prazos pactuados para a organização dos eventos esportivos sediados no País. Assim, a lei busca a otimização do tempo, dos procedimentos e dos recursos disponíveis.

Joel de Menezes Niebuhr (2013, p. 655) ressalta que o tempo, a necessidade de celeridade que a Lei $n^{0} 8.666 / 1993$ não apresentava-foi a grande questão para a criação do Regime Diferenciado de Contratações-mas que grande parte de suas normas não tem qualquer relação com o encurtamento de prazos da licitação, visando a outros objetivos.

No que concerne à busca pela eficiência, Marçal Justen Filho (2013, p. 42) assinala ser uma problemática que vem assombrando os agentes públicos e a doutrina especializada, mas que, no caso de sua orientação como diretriz do Regime Diferenciado de Contratações, deve ser interpretada de maneira distinta. $\mathrm{O}$ autor afirma que as soluções apresentadas nos outros regimes licitatórios, por mais que estes também busquem a eficiência, não são satisfatórias para assegurá-la. Desse modo, por meio do novo regime, o legislador cria um modelo licitatório que visa a promover a eficiência, a qual pode ser compreendida em três manifestações distintas: redução de tempo, redução de custos e ampliação de vantagens.

O novo diploma traz uma série de dispositivos vinculados à busca pela eficiência, dentre eles: o sigilo no orçamento, a exigências diferenciadas para a aquisição de bens, a remuneração variável vinculada ao desempenho da contratada, a contratação simultânea e alterações no procedimento licitatório, com destaque para a inversão das fases de habilitação e julgamento, e a Contratação Integrada. 


\section{a) Sigilo no orçamento}

A Lei Federal $n^{0} 12.462 / 2011$ prevê no seu art. $6^{012}$ a não divulgação do orçamento estimado para a licitação do objeto licitado; assim, o orçamento será tornado público somente após o fim da licitação, momento que o Decreto $\mathrm{n}^{\mathrm{o}} 7.581 / 2011$ define como o da adjudicação do objeto. Os parágrafos $1^{\circ}$ e $2^{\circ}$ trazem as exceções à regra, que se relacionam às modalidades de julgamento por maior desconto e melhor técnica.

O sigilo no orçamento não encontra correspondência na Lei Federal $n^{0} 8.666 / 1993$. A justificativa para a inserção desse instituto no Regime Diferenciado de Contratações está no argumento da Administração de que a divulgação do orçamento é prejudicial à competitividade do certame, porque faz com que os licitantes balizem suas propostas por ele, o que representa freios à disputa; nessa linha de pensamento, se não houvesse esta baliza na sua formulação, as propostas teriam os valores reduzidos (NIEBUHR, 2013, p. 668).

Este foi o argumento expressado tanto nas discussões para a aprovação do texto da Medida Provisória $n^{\circ}$ 527/2011 quanto nas informações prestadas pela Presidente da República no âmbito das Ações Diretas de Inconstitucionalidade perante o Supremo Tribunal Federal, em que afirma ser um mecanismo de proteção ao erário, atendendo ao princípio da eficiência e economicidade. Há também menção sobre o funcionamento dessa prática em países da Europa e Estados Unidos (CARDOSO, 2012, p. 84).

12 Art. $6^{\circ}$ Observado o disposto no $\S 3^{\circ}$, o orçamento previamente estimado para a contratação será tornado público apenas e imediatamente após o encerramento da licitação, sem prejuízo da divulgação do detalhamento dos quantitativos e das demais informações necessárias para a elaboração das propostas.

$\S 1^{\circ}$ Nas hipóteses em que for adotado o critério de julgamento por maior desconto, a informação de que trata o caput deste artigo constará do instrumento convocatório.

$\S 2^{\circ}$ No caso de julgamento por melhor técnica, o valor do prêmio ou da remuneração será incluído no instrumento convocatório.

$\S 3^{\circ}$ Se não constar do instrumento convocatório, a informação referida no caput deste artigo possuirá caráter sigiloso e será disponibilizada estrita e permanentemente aos órgãos de controle externo e interno. (BRASIL, 2011). 
Os debates não fazem referência a demonstrações objetivas dessa premissa nesses países, mas a doutrina internacional reconhece o efeito com base na aplicação de uma teoria econômica chamada auctions theory (teoria dos leilões). Ela reconhece que os processos licitatórios têm estrutura aproximada à de um leilão, e, assim, o grau de informação disponibilizado por uma das partes influenciará necessariamente no comportamento da outra (CARDOSO, 2012, p. 85).

$\mathrm{O}$ sigilo do orçamento tem a sua constitucionalidade questionada, em virtude de que representaria uma afronta ao princípio da publicidade. No entanto, o princípio da publicidade não é absoluto e deve ser ponderado com outros sob o caso concreto. Nesse caso, ele está em confronto com os princípios da competitividade, eficiência e economicidade, prevalecendo o interesse público na relativização (NIEBUHR, 2013, p. 668).

Cumpre ressaltar que o sigilo no orçamento não importa na ausência de controle, pois, como de acordo com o $\S 3^{\circ}$ do art. $6^{\circ}$, a vedação à divulgação do orçamento não se aplica aos órgãos de controle externo e interno. Não há impedimento ao exercício das atividades de fiscalização sobre a regularidade da atividade administrativa (JUSTEN FILHO, 2012, p. 113).

Não há norma constitucional que preveja a obrigatoriedade de divulgação do orçamento estimado no momento da publicação do edital para o chamamento dos interessados, nem mesmo o princípio da publicidade. Do princípio da publicidade resulta tão somente o dever geral de publicidade dos atos administrativos, o qual pode inclusive ser mitigado em determinadas hipóteses (CARDOSO, 2012, p. 84).

\section{b) Exigências diferenciadas para aquisição de bens}

De acordo com Joel de Menezes Niebuhr (2013, p. 669), um dos grandes problemas da legislação sobre licitações está na ausência de previsão de instrumentos que permitam a análise da 
qualidade dos objetos ofertados à Administração. Em nome da competividade, isonomia e julgamento objetivo, muitas vezes o administrador se vê de mãos atadas, forçado a aceitar proposta que, mesmo atendendo às regras do edital, sabe de antemão que não irá atender efetivamente às suas atividades e necessidades.

O Regime Diferenciado de Contratações traz em seu art. $7^{013}$ possibilidades no que diz respeito à avaliação das propostas. Elas consistem na possibilidade de indicação de marca e modelo, dentro de certas hipóteses, de exigir amostras, de solicitar certificação e carta de solidariedade do fabricante.

Quanto à indicação de marca e modelo, não há grandes inovações. A Lei Federal no 12.462/2011 reproduz o que se já vinha permitindo na sistemática tradicional de licitações. A delimitação de marca e modelo permite maior agilidade e o atendimento ao princípio da padronização, embora requeira fundamentação consistente para não prejudicar a isonomia entre os licitantes (TROIB, 2012, p. 109).

A Lei Federal $n^{0} 12.462 / 2011$ inova ao prever expressamente a possibilidade de exigência de amostra para a aquisição de bens. A exigência de amostras é bastante usual nas licitações, principalmente sob a modalidade pregão. Mas é fonte constante de disputas, inclusive questionando a sua legalidade, justamente por não haver previsão legal a seu respeito e ao

13 Art. $7^{\circ}$ No caso de licitação para aquisição de bens, a administração pública poderá:

I-indicar marca ou modelo, desde que formalmente justificado, nas seguintes hipóteses:

a) em decorrência da necessidade de padronização do objeto;

b) quando determinada marca ou modelo comercializado por mais de um fornecedor

for a única capaz de atender às necessidades da entidade contratante; ou

c) quando a descrição do objeto a ser licitado puder ser melhor compreendida pela identificação de determinada marca ou modelo aptos a servir como referência, situação em que será obrigatório o acréscimo da expressão "ou similar ou de melhor qualidade";

II-exigir amostra do bem no procedimento de pré-qualificação, na fase de julgamento das propostas ou de lances, desde que justificada a necessidade da sua apresentação; III-solicitar a certificação da qualidade do produto ou do processo de fabricação, inclusive sob o aspecto ambiental, por qualquer instituição oficial competente ou por entidade credenciada; e

IV-solicitar, motivadamente, carta de solidariedade emitida pelo fabricante, que assegure a execução do contrato, no caso de licitante revendedor ou distribuidor. 
procedimento a ser seguido pela Administração ${ }^{14}$. O Regime Diferenciado de Contratações, além de permitir a exigência, prevê o momento em que a Administração poderá fazê-la: tanto na fase de pré-qualificação como na fase de julgamento das propostas (ROST, 2012, p. 112).

Quanto à exigência de certificação, Joel Menezes Niebuhr (2012, p. 670), sustenta que os interessados em participar de licitações não podem ser impedidos por não dispor de certificações privadas, uma vez que ninguém pode ser prejudicado previamente por não a obter. Alerta que o dispositivo pode gerar muitos litígios, e que, para evitá-los, a Administração deve usá-lo com parcimônia. Nesse sentido, somente se devem exigir certificações quando forem absolutamente justificadas, isto é, quando normalmente delas dispuserem as empresas do mercado e quando sejam passíveis de rápida obtenção, dentro do prazo do edital.

A última exigência possibilitada pelo art. $7^{\circ}$ é a de carta de solidariedade, que é um documento firmado pelo fabricante do bem em questão em favor do licitante, na qual estabelece responsabilidade recíproca sobre o bem a ser fornecido no procedimento licitatório. Deve-se notar, contudo, que a prática de solicitação de carta de solidariedade é comum em várias esferas do governo mesmo antes da previsão legal da Lei Federal $\mathrm{n}^{\mathrm{o}}$ 12.462/2011 (ROST, 2012, p. 120).

\section{c) Contratação integrada}

A Lei Federal no 12.462/2011 admite, em seu art. $8^{\circ}$, cinco regimes de execução indireta ${ }^{15}$ para obras e serviços de engenharia: empreitada por preço unitário, empreitada por preço global, contratação por tarefa, empreitada integral e contratação integrada.

14 A legalidade da exigência, no entanto, já é pacífica na doutrina e jurisprudência.

15 Aquela em que o órgão ou a entidade contrata com terceiros obras ou serviços, consubstanciando em uma empreitada (MOTTA; BICALHO, 2012, p. 128). 
Dentre os regimes de execução mencionados, a Contratação Integrada é o único sem previsão na Lei Federal $n^{\circ}$ 8.666/1993. É, assim, uma das novidades do Regime Diferenciado de Contratação.

A contratação integrada é disciplinada pelo art. $9^{\circ}$ da Lei ${ }^{\circ}$ 12.462/2011 e representa um dos maiores pontos de discórdia do novo regime. A normativa vem sido compreendida e interpretada por diferentes ângulos, atraindo, inclusive, manifestações passionais. Esse regime de execução apresenta como principal característica a dispensa do projeto básico no procedimento licitatório, peculiaridade que, como leciona Joel Menezes Niebuhr (2013 p. 658), tem gerado tamanho entrevero.

A definição da contratação integrada pode ser percebida no próprio texto do Regime Diferenciado de Contratações, que dispõe no primeiro parágrafo do art. $9^{\circ}$ que esta "compreende a elaboração e o desenvolvimento dos projetos básico e executivo, a execução de obras e serviços de engenharia, a montagem, a realização de testes, a pré-operação e todas as demais operações necessárias e suficientes para a entrega final do objeto". (BRASIL, 2011).

\section{O PROCEDIMENTO LICITATÓRIO NO REGIME DIFERENCIADO DE CONTRATAÇÃO}

O procedimento licitatório do Regime Diferenciado de Contratação não se confunde com os procedimentos estabelecidos na legislação anterior, já que a nova lei estabelece uma nova modalidade de licitação, cujas regras devem ser interpretadas coerentemente (PEREIRA, 2012, p. 193).

Joel Menezes Niebuhr (2013, p. 673) afirma que a principal característica das licitações do Regime Diferenciado de Contratações é a aproximação da sistemática do pregão. A Lei 
Federal $\mathrm{n}^{\mathrm{o}} 12.462 / 2011$ traz modalidade que apresenta a inversão de fases, etapa de lances, oportunidade única para a interposição de recursos, com a necessidade de prévia manifestação da intenção de recurso e a preferência pela forma eletrônica. As semelhanças são evidentes; nas palavras do autor: "pode-se até dizer que o RDC é um pregão disfarçado, com andar meio esquisito, talvez até mais glamour, mas, em essência [...] algo muito próximo do pregão, ou o próprio pregão com nome diferente". (NIEBUHR, 2013, p. 673).

Também sustenta que as vantagens divulgadas sobre o novo regime, acerca da redução de tempo e do valor das contrações, remetem às características já presentes na modalidade pregão. O jurista considera que a redução de tempo está relacionada à inversão de fases de julgamento e à concentração de recursos no final da licitação; já a redução do preço é atribuída à etapa de lances e possivelmente ao sigilo do orçamento, o que demandaria estudo prático mais aprofundado (NIEBUHR, 2013, p. 673).

Como explicitado, a Lei Geral de Licitações - Lei Federal $\mathrm{n}^{\mathrm{o}} 8.666 / 1993$ foi o primeiro diploma legal da matéria de licitações que passou pelos trâmites de um processo legislativo democrático. No entanto, a democracia era ainda incipiente, e o Brasil passava por um momento político delicado, marcado por escândalos e desvios de corrupção. A Lei Geral de Licitações foi promulgada em meio a esperanças de moralização. A alternativa adotada pelo legislador como "meio" para este fim foi a diminuição da discricionariedade do administrador no procedimento licitatório. Assim, a Lei Federal no 8.666/1993 se enquadraria ao que André Janjácomo Rosilho (2011, p. 22) chama de modelo licitatório maximalista, no qual a discricionariedade é temida, de vez que se parte da premissa de que os agentes públicos não são confiáveis, sendo então necessário limitar sua mobilidade:

Para tanto, o maximalismo aposta que as normas devem ser 
detalhistas, minuciosas e abrangentes, restringindo ao máximo a margem de liberdade daqueles que a elas se submetem. É interessante notar que a supervalorização das regras em detrimento do juízo dos homens reflete, ao mesmo tempo, a valorização do tratamento justo e imparcial e o receio - ou crença - de que não se possa atingi-lo por meio do julgamento dos indivíduos. (ROSILHO, 2011, p. 22).

O Regime Diferenciado de Contratações está mais aproximado do modelo minimalista, porquanto abre espaço para uma atuação mais ativa do agente público no seu procedimento. Ademais, o minimalismo não entende a discricionariedade como um câncer do sistema; antes, esta é um componente importante a ser trabalhado na legislação para que a licitação atinja os fins desejados (ROSILHO, 2011, p. 21).

Benjamin Zymler, Ministro do Tribunal de Contas da União, comenta em depoimento a ampliação da discricionariedade no novo regime e destaca a necessidade de qualificação do gestor público que irá atuar no âmbito do Regime Diferenciado de Contratações, visto que o Regime oferece opções discricionárias complexas e exige do gestor maior conhecimento técnico. Nas palavras do Ministro, o RDC "não é uma receita de bolo como a Lei no 8.666".

O discurso moralizador que acompanhou a tramitação da Lei Federal no 8.666/1993 permite a compreensão de algumas críticas direcionadas ao novo regime. Por exemplo: na argumentação da Ação Direta de Inconstitucionalidade, o Procurador-Geral da República questiona a constitucionalidade do novo regime e adota, em diversos momentos, como parâmetro de comparação, os dispositivos da Lei Federal nº 8.666/1993, e não da Constituição Federal, como se somente os seus procedimentos fossem aceitos pelo Direito Brasileiro ${ }^{16}$.

16 Como pode-se perceber em trecho da inicial: "É tamanha a importância da preexistência do projeto básico que o art. $7^{\circ}, \S 2^{\circ}$ da Lei $\mathrm{n}^{\circ} 8.666$ somente admite a abertura de licitação para obras e serviços quando "houver projeto básico aprovado pela autoridade competente e disponível para exame dos interessados em participar 
Assim, o Regime Diferenciado de Contratação, ao afastar as normas vigentes sobre licitações, estaria cometendo atentado à própria moralidade e às conquistas da sociedade, supostamente estampadas na Lei $\mathrm{n}^{\circ} 8.666 / 93$, em prol da boa administração. Para aqueles que partilham desta visão de mundo, as iniciativas de reforma no sistema de licitações e contratos, em geral, costumam ser automaticamente percebidas com enorme desconfiança, como se o real móvel para mudanças fossem razões e interesses escusos. (ROSILHO, 2012, p. 12).

Ressalta-se que esta não é uma defesa da constitucionalidade da Lei Federal no 12.462; este não é o objetivo deste trabalho. Apenas aponta-se o fato de que, na propositura da ADI, a Lei Federal no 8.666/1993 é metaforicamente elevada a status de lei maior para "medir" a constitucionalidade do novo regime.

Os debates entre críticos e defensores da Lei Federal $n^{\circ}$ 12.462/2011 e dos seus institutos têm sido bastante acalorados, Marçal Justen Filho aponta que a ausência de objetividade na avaliação das virtudes e dos defeitos do novo diploma é um problema sério: os seus defensores tendem a ignorar as limitações e valorizar as virtudes do RDC, ao compasso que os seus críticos enxergam defeitos inexistentes e menosprezam as suas vantagens. Segundo o autor a avaliação desapaixonada do novo sistema é um grande desafio (JUSTEN FILHO, 2013, p. 22).

\section{CONCLUSÃO}

O Regime Diferenciado de Contratações surgiu em meio de um cenário de descontentamento com a disciplina licitatória vigente, como as críticas não apresentavam consenso algum para direcionar qualquer mudança, aproveitou-se da justificativa da Copa do Mundo e dos Jogos Olímpicos para testar-se um modelo diferente.

Como abordado, a Lei Federal no 8.666/1993, apesar de ser do procedimento licitatório”. (BRASIL, 1993). 
o primeiro diploma da matéria de licitações e contratos efetivamente democrático, foi concebida em um período bastante conturbado politicamente. O procedimento de licitação era encarado como um meio de combate à corrupção, havia maior preocupação com a legalidade do que com a eficiência, no o que pode se chamar de uma cultura de procedimento em oposição a uma cultura de resultado.

Neste ânimo, a Lei Federal $n^{\circ}$ 8.666/1993 apresenta um texto exaustivo, independente de Decreto Regulamentar, no qual a discricionariedade do administrador é cerceada e a função dos agentes públicos diminuída. Este "engessamento" da atividade administrativa, no entanto, não serviu para que o objetivo da lei - de impossibilitar a imoralidade na licitação pública - fosse alcançado, mas colaborou para a ineficiência das contratações públicas.

Neste trabalho verificou-se que, no Regime Diferenciado de Contratações há um aumento da discricionariedade do agente administrativo no procedimento de licitação. Afinal, um modelo diferenciado que se propõe a apresentar soluções diferenciadas não pode ser construído sob a mesma lógica do modelo já existente. Como destacado, parte da resistência ao Regime Diferenciado de Contratação está ligada ao fato de ele ser medido com a "régua" da Lei Federal nº 8.666/1993.

Porém, da mesma forma que a redução da discricionariedade do administrador não implicou em maior moralidade nas licitações, o aumento da discricionariedade não significa que haverá maior ganho de eficiência, pois se trata de uma medida que oferece uma série de desafios a administração, exigindo maior competência técnica dos seus operadores para exercitar esta maior liberdade. 


\section{REFERÊNCIAS}

ANDRADE, Ricardo Barretto de; VELOSO, Vitor Lanza. Uma visão geral sobre o regime diferenciado de contratações públicas: objetos, objetivos, definições, princípios e diretrizes. In: JUSTEN FILHO, Marçal; PEREIRA, Cesar A. Guimarães (Orgs.). $O$ Regime Diferenciado de Contratações Públicas. Belo Horizonte: Fórum, 2012.

AÇÃO do MPF questiona no Supremo regime de contratações públicas para obras da Copa. In: Notícias STF. Disponível em:

$<$ http://www.stf.jus.br/portal/cms/verNoticiaDetalhe.asp?idConteudo=188758 $>$. Acesso em: 1 abr. 2014.

AÇÃO QUE questiona regime de contratações para obras da Copa terá rito abreviado, In: Notícias STF. Disponível em: < http://www.stf.jus.br/portal/cms/verNoticiaDetalhe. asp?idConteudo=188346> . Acesso em: 28 abr. 2014.

AMORA, Dimmi. Petrobrás fecha R\$90 bilhões em contratos sem licitação. Disponível em: < http://www1.folha.uol.com.br/poder/2014/04/1436864-petrobras-fecha-r-90-bi-em-contratos-sem-licitacao.shtml > . Acesso em: 2 maio 2014.

BRASIL. Constituição (1988). Constituição da República Federativa do Brasil. Disponível em: <http://www.planalto.gov.br/ccivil_03/constituicao/constituicao.htm>. Acesso em: 28 abr. 2014.

BRASIL. Lei n. 8.666, de 21 de junho de 1993. Regulamenta o art. 37, inciso XXI, da Constituição Federal, institui normas para licitações e contratos da Administração Pública e dá outras providências. Disponível em: <http://www.planalto.gov.br/ccivil_03/ leis/18666cons.htm>. Acesso em: 28 abr. 2014.

BRASIL. Lei $n$. 8.987, de 13 de fevereiro de 1995. Dispõe sobre o regime de concessão e permissão da prestação de serviços públicos previsto no art. 175 da Constituição Federal, e dá outras providências. Disponível em: < http://www.planalto.gov.br/ccivil_03/ leis/18987cons.htm>. Acesso em: 28 abr. 2014.

BRASIL. Lei $n$. 12.462, de 4 de agosto de 2011. Institui o Regime Diferenciado de Contratações Públicas-RDC; altera a Lei no 10.683, de 28 de maio de 2003 [...] Disponível em: <http://www.planalto.gov.br/ccivil_03/_ato2011-2014/2011/Lei/L12462. htm>. Acesso em: 28 abr. 2014.

BRASIL. Lei n. 11.079, de 30 de dezembro de 2004. Institui normas gerais para licitação e contratação de parceria público-privada no âmbito da administração pública. Disponível em: <http://www.planalto.gov.br/ccivil_03/_ato2004-2006/2004/lei/111079. htm>. Acesso em: 28 abr. 2014.

BRASIL. Decreto Federal n. 2.745, de 24 de agosto de 1998. Aprova o Regulamento do Procedimento Licitatório Simplificado da Petróleo Brasileiro S.A.-PETROBRÁS previsto no art . 67 da Lei no 9.478, de 6 de agosto de 1997. Disponível em: <http:// www.planalto.gov.br/ccivil_03/decreto/D2745.htm>. Acesso em: 28 abr. 2014.

BRASIL. Decreto Federal n. 8.080, de 20 de agosto de 2013. Altera o Decreto $\mathrm{n}^{\mathrm{o}}$ 7.581, de 11 de outubro de 2011, que regulamenta o Regime Diferenciado de Contratações Públicas-RDC, de que trata a Lei $n^{\circ} 12.462$, de 5 de agosto de 2011. Disponível em: <http://www.planalto.gov.br/ccivil_03/_ato2011-2014/2013/Decreto/D8080. 
htm>. Acesso em: 28 abr. 2014.

BRASIL. Decreto Federal n. 7.581, de 11 de outubro de 2011. Regulamenta o Regime Diferenciado de Contratações Públicas-RDC, de que trata a Lei no 12.462 , de 5 de agosto de 2011. Disponível em: <http://www.planalto.gov.br/ccivil_03/_ato20112014/2011/Decreto/D7581.htm>. Acesso em: 28 de abr. de 2014.

BICALHO, Alécia Paolucci Nogueira. Novo horizonte para as obras públicas. Revista Zênite-Informativo de Licitações e Contratos (ILC), Curitiba: Zênite, n. 237, p. 11431144, nov. 2013.

BORGES, Gabriela Lira. Alocação de riscos na contratação integrada: Considerações sobre a matriz e a taxa de risco. Revista Zênite-Informativo de Licitações e Contratos (ILC), Curitiba: Zênite, n. 240, p. 164-168, fev. 2014.

CARDOSO, André Guskow. O regime diferenciado de contratações públicas: questão da publicidade do orçamento estimado. In: JUSTEN FILHO, Marçal; PEREIRA, Cesar A. Guimarães (Orgs.) O regime diferenciado de contratações públicas. Belo Horizonte: Fórum, 2012.

CARVALHO FILHO, José dos Santos. Manual de direito administrativo. São Paulo: Atlas, 2012.

CONSELHO FEDERAL DE ENGENHARIA E AGRONOMIA, Resolução $n o$ 361/91. Disponível em: < http://normativos.confea.org.br/ementas/lista_ementas.asp >. Acesso em: 2 abr. 2014.

DAL POZZO, Augusto Neves. Panorama geral dos regimes de execução previstos no regime diferenciado de contratações: a contratação integrada e seus reflexos. In: CAMMAROSANO, Márcios; DAL POZZO, Augusto Neves; VALIM, Rafael (Orgs.) Regime diferenciado de contratações públicas: aspectos fundamentais. Belo Horizonte: Fórum, 2012.

DI PIETRO, Maria Sylvia Zanella. Direito administrativo. São Paulo: Atlas, 2012.

GEROLLA, Giovanny. RDC: riscos da contratação integrada. In: PINI - Edição 36 - março/2014. Disponível em: <http://infraestruturaurbana.pini.com.br/solucoes-tecnicas/36/rdc-riscos-da-contratacao-integrada-307710-1.aspx>. Acesso em: 24 mar. 2014.

GURGEL, Roberto. Petição Inicial ADI 4655. Disponível em:

$<$ http://redir.stf.jus.br/estfvisualizadorpub/jsp/consultarprocessoeletronico/ConsultarProConsultarProces.jsf?seqobjetoincidente=4138546> . Acesso em: 28 abr. 2014.

JUSTEN FILHO, Marçal. Comentários ao RDC. São Paulo: Dialética, 2013. tica, 2013.

Comentários a lei de licitações e contratos administrativos. São Paulo: Dialé-

MELLO, Celso Antônio Bandeira de. Curso de direito administrativo. São Paulo: Malheiros, 2008.

MOREIRA, EgonBockmann; GUIMARÃES, Fernando Vernalha. Licitação pública: a Lei Geral de Licitação - LGL e o Regime Diferenciado de Contratação - RDC. São Paulo: Malheiros, 2012.

MOTTA, Carolos Pinto Coelho; BICALHO, Alécia Paolucci Nogueira. RDC: contra- 
tações para as copas e jogos olímpicos. Belo Horizonte: Fórum, 2012.

MOTTA, Carlos Pinto Coelho. Eficácia nas concessões, permissões e parcerias. Belo Horizonte: Del Rey, 2007.

. Eficácia nas licitações e contratos. Belo Horizonte: Del Rey, 2005.

MIGUEL, Luiz Felipe Hadlich. Licitação: passado, presente e futuro. In: ALMEIDA, Fernando Dias de; MARQUES NETO, Floriano de Azevedo; MIGUEL, Luiz Felipe Hadlich (coords.). Direito Público em Evolução. Belo Horizonte: Fórum, 2013.

MIRANDA, Thiago. Comissão aprova regime diferenciado para todas as licitações e contratos públicos. In: Agência Câmara Noticias. Disponível em: $<$ http://www2.camara.leg.br/camaranoticias/noticias/ADMINISTRACAO-PUBLICA/464447-COMISSAO-APROVA-REGIME-DIFERENCIADO-PARA-TODAS-AS-LICITACOES-E-CONTRATOS-PUBLICOS.html > Acesso em: 18 de abr. 2014.

NÓBREGA, Marcos. Direito da infraestrutura. São Paulo: Quartien Latin, 2011.

NIEBUHR, Joel Menezes. Licitação pública e contrato administrativo. Belo Horizonte: Fórum, 2013.

Reforma da legislação sobre licitação pública: projeto de lei $\mathrm{n}^{\mathrm{o}} 32$, do Senado Federal. In: Zênite Revista Digital. Publicado em outubro/2009. Disponível em: <https:/www.webzenite.com.br/documentoscliente/c3c1673a-aalb-4721-9e0571494e509566>. Acesso em: 20 abr. 2014.

PEREIRA JÚNIOR, Jessé Torres; DOTTI, Maria Restelato. Execução indireta de obras e serviços de engenharia e seus respectivos projetos (básico e executivo) no regime diferenciado de contratação. Revista SÍNTESE Direito Administrativo, São Paulo, n. 78, 2012.

PINTO, Marcos Barbosa. Panorama da nova disciplina legislativa. In: TALAMINI, Eduardo; JUSTEN, Monica Spezia (Coord.). Parcerias público-privadas. São Paulo: Revista dos Tribunais, 2005.

RÊGO, Eduardo de Carvalho. A ampliação do regime diferenciado de contratações públicas e a transformação de sua finalidade inicial. Revista Zênite - Informativo de Licitações e Contratos (ILC), Curitiba: Zênite, n. 226, p. 1232-1233, dez. 2012.

REISDORFER, Guilherme Fredherico Dias. A contratação integrada no regime diferenciado de contratações públicas. In: JUSTEN FILHO, Marçal; PEREIRA, Cesar A. Guimarães (Orgs.) O regime diferenciado de contratações públicas. Belo Horizonte, Editora Fórum, 2012.

ROSILHO, André Janjácomo. Qual é o modelo legal das licitações no Brasil? As reformas legislativas federais no sistema de contratações públicas. Dissertação de Mestrado, FVG, São Paulo, 2011.

ROST, Maria Augusta. As exigências de amostra e carta de solidariedade. In: JUSTEN FILHO, Marçal; PEREIRA, Cesar A. Guimarães (Orgs.) $O$ Regime Diferenciado de Contratações Públicas. Belo Horizonte: Fórum, 2012.

RIBEIRO, Maurício Portugal; Concessões e PPP`s: melhores práticas em licitações e contratos. São Paulo: Atlas, 2011.

SANTA CATARINA. Decreto $n^{o}$ 1.537/2013. Disponível em: <http://server03.pge. 
sc.gov.br/LegislacaoEstadual/2013/001537-005-0-2013-004.htm> Acesso em: 28 abr. 2014.

SCHIEFLER, Gustavo Henrique Carvalho. Procedimento de Manifestação de Interesse (PMI): solicitação e apresentação de estudos e projetos para a estruturação de concessões comuns e parcerias público-privadas. Dissertação de Mestrado, UFSC, 2013.

SCHWIND, Rafael Wallbach. Remuneração variável e contratos de eficiência no Regime Diferenciado de Contratações Públicas. In: JUSTEN FILHO, Marçal; PEREIRA, Cesar A. Guimarães (Orgs.) O regime diferenciado de contratações públicas. Belo Horizonte: Fórum, 2012.

SOBRE o pacto por Santa Catarina, In: PACTO por Santa Catarina - Governo do Estado. Disponível em: <http://www.pactoporsc.sc.gov.br/index.php/sobre-o-pacto $>$. Acesso em: 28 abr. 2014.

TROIB, Alan Garcia. A indicação de marcas ou modelos para a aquisição de bens. In: JUSTEN FILHO, Marçal; PEREIRA, Cesar A. Guimarães (Orgs.) O regime diferenciado de contratações públicas. Belo Horizonte: Fórum, 2012.

Artigo recebido em 20/05/2016

Artigo aprovado em 18/07/2016 